\title{
A produção científica: esforços docentes e discentes vividos e sentidos
}

\author{
DOI: http://dx.doi.org/10.20435/inter.v19i4.2177
}

A produção científica é, no âmbito brasileiro e internacional, a forma mais eficaz de transmissão de conhecimentos, descobertas e teorias, com o objetivo de garantir o desenvolvimento de uma região/ país, quebrar paradigmas e melhorar a qualidade de vida. E é somente por meio da divulgação e popularização desse novo conhecimento que haverá uma contribuição no desenvolvimento humano e social. Desse modo, é observado assim o inegável papel da ciência para dar existência e materialidade a objetos e teorias jamais utilizadas anteriormente e que hoje se encontram em nosso cotidiano. Na convivência com alguns colegas, seja no papel de editora, seja no de docente na academia há mais de vinte anos e a partir de pesquisas e trabalhos já publicados, temos nos deparado com uma situação paradoxal: de um lado, a visão de que indivíduos isolados não podem fazer ciência, e de outro, as condições para fazer parte de uma comunidade científica que exigem dos docentes e alunos um esforço permanente para a construção do conhecimento com a certeza de poder pertencer a uma comunidade científica.

Mas, para que haja a devida comunicação e divulgação da ciência, é essencial que o pesquisador leve em consideração qual canal comunicativo deverá usar, não somente para garantir visibilidade ao seu trabalho, mas também para possibilitar que outros pesquisadores possam ter acesso a esse conhecimento. Assim, a função primordial da comunicação científica é dar continuidade a esse conhecimento, difundindo-o a outros estudiosos que, a partir daí, poderão desenvolver pesquisas para validar ou contestar os resultados de investigações anteriores ou instituir novos objetivos nas áreas de interesse (FUNARO, 2010).

Nesse contexto, é relevante o papel da dedicação docente ao estudo, pesquisa, divulgação e orientação de trabalhos voltados à elaboração do texto científico, em cursos de graduação e Pós-graduação lato sensu e stricto sensu, na orientação em iniciação científica, face às dificuldades percebidas nos alunos, no tocante à elaboração de produções textuais tanto relativas às estruturas formais quanto às estruturas textuais, qualidades estas necessárias na academia. A divulgação científica, considerada um gênero particular discursivo, é responsável por transpor um discurso específico de uma esfera do campo científico para a comunidade em geral, de acordo com Reis (1964, p. 23), "é por meio do texto de divulgação científica que a sociedade entra em contato com as pesquisas que estão sendo realizadas, dos experimentos em andamento".

No entanto a grande problemática encontrada hoje no contexto brasileiro é que a maioria dos graduandos e pós-graduandos, sobre quem recai a maior exigência acerca da pesquisa científica e da produção textual, possui extrema dificuldade na leitura e produção científico-acadêmica. Ou seja, não possui a habilidade de, diante de uma análise metodológica, elaborar a produção de um artigo, de apresentar um trabalho de conclusão de curso e de utilizar, de forma correta, as citações tão fundamentais na correlação dos diferentes autores, necessidade básica levando-se em conta o embasamento teórico.

O domínio de uma leitura crítica tem como consequência uma maior habilidade na produção escrita científico-acadêmica e, nesse contexto, é clara a importância da relação entre leitura e produção de textos, pois o estudante que lê, satisfatoriamente, consegue estabelecer relações dialógicas com textos de outros interlocutores(as) e seus próprios textos, aprimorando as condições de recepção e produção destes.

Amplia essa questão Santos (2006, p. 82), para quem a importância de uma leitura crítica é caminho para desenvolver as habilidades de produção textual, pois para a autor a efetivação do domínio da capacidade de leitura é a base central para a efetivação da aprendizagem, e ela enfatiza esta questão quando afirma que "O ato de ler e o de aprender são duas realidades muito próximas, portanto indissociáveis, interferindo-se mutuamente".

Contudo, ao lado da já enfatizada necessidade da leitura crítica em relação à temática em estudo, deve-se ter um bom domínio das estruturas textuais e formais: como elaborar um artigo científico? Como publicar em uma revista científica com bom qualis? Como não plagiar? Todos esses questionamentos, 
são muito comuns na esfera acadêmica, principalmente àqueles que estão iniciando a vida universitária e, quando não elucidados, contribuem para a péssima qualidade de um texto científico.

É fundamental, portanto, o papel da divulgação científica com relação às produções textuais, e ela vem evoluindo ao longo do tempo, acompanhando o próprio desenvolvimento da ciência e tecnologia e tem se orientado para diferentes objetivos. O primeiro é referente à educação científica em função da necessidade da ampliação do conhecimento e da compreensão do público leigo a respeito do processo científico e sua lógica, da transmissão da informação científica, com o objetivo de esclarecimento dos indivíduos sobre o desvendamento e a solução de problemas relacionados a fenômenos cientificamente estudados. É importante reforçar, segundo Albagli (1996), a transmissão de informação científica que possa instrumentalizar os atores a intervir melhor no processo decisório.

Com relação a essa discussão, o v. 19, n. 4 de 2018 traz em seus artigos uma visão interdisciplinar como um fenômeno capaz de permitir a interação entre as disciplinas diversas, como uma forma de tentar explicar a complexidade dos problemas humanos e dar conta das dinâmicas relacionais existentes.

Neste volume, encontramos uma diversidade de interfaces temáticas que discutem do direito à cidade e o desenvolvimento local, à questão do planejamento urbano contemporâneo; na saúde, os cuidados paliativos oncológicos à utilização de ácidos graxos no sangue de gestantes. Na educação, desde a avaliação da bolsa família ao campo da educação cooperativista, assim como aos estudos rurais brasileiros e o papel do ambiente escolar na cultura alimentar. A natureza do Pantanal é vivificada como também a percepção dos pescadores artesanais.

Interações, Revista Internacional de Desenvolvimento Local, chega ao seu volume 19, quarto número do ano de 2018, com muitas motivações e agradecimentos. Agradecer aos professores avaliadores, seja da Comissão Editorial, sejam avaliadores ad hoc, que não têm medido esforços em atender aos nossos pedidos de avaliação. Agradecemos também ao crescimento do número de colaboradores e do interesse internacional por essa publicação, fato que contribui para a manutenção dos padrões científicos desse periódico. Outro fator importante é o aumento substancial de artigos submetidos na revista em diferentes áreas, demonstrando cada vez mais o caráter interdisciplinar proposto pela Revista.

A diversidade de abordagens dos temas relacionados ao Desenvolvimento Local também demonstra a grande potencialidade dessa nova perspectiva social em que as comunidades tomam suas relações internas (culturais, organizacionais, produtivas e econômicas) como seu próprio objeto de aprimoramento. Para 2019, a revista passa a privilegiar a publicação de dossiês temáticos e específicos, além de números especiais, voltados a eventos locais, regionais, nacionais e internacionais, dos quais a Universidade participa e que tenham relevância científica para a revista de acordo com as linhas de pesquisa vigentes no Programa de Pós-Graduação em Desenvolvimento Local (PPGDL).

\section{Profa. Dra. Arlinda Cantero Dorsa ${ }^{1}$ Editora Chefe da Interações}

\section{REFERÊNCIAS}

ALBAGLI, S. Divulgação científica: informação científica para a cidadania? Ciência da Informação, Brasília, v. 25, n. 3, p. 396-404, set./dez. 1996.

FUNARO, V. M. B. O. Rede colaborativa entre autores em odontologia: docentes dos programas de pós-graduação credenciados em universidades participantes do sistema de informação especializado na área de odontologia (SIEO). 2010. 184 f. Tese (Doutorado em Ciência da Informação) - Escola de Comunicações e Artes, Universidade de São Paulo (USP), São Paulo, 2010.

REIS, J. A. Divulgação científica e o ensino. Ciência e Cultura, São Paulo, v. 16, n. 4, 1964.

SANTOS, S. J. B. A importância da leitura no ensino superior. Revista de Educação, Londrina, PR, v. 9, n. 9, p. 77-83, 2006.

${ }^{1}$ Universidade Católica Dom Bosco (UCDB), Campo Grande, Mato Grosso do Sul, Brasil. 